\title{
CÂNONE E VESTIBULAR: EXCLUSÃO, ELEIÇÃO E RECORRÊNCIA NO VESTIBULAR DA UFMG
}

RESUMO:

Este texto pretende manter a discussão sobre o cânone no vestibular, utilizando, para isso, dados comparativos da indicação de obras durante os trinta anos de vestibular unificado da UFMG (1970-2000). Por meio desse estudo, queremos dizer que o vestibular da UFMG tem propiciado a abertura do cânone e a manutenção da leitura de obras em níveis diferentes de canonização no cenário cultural, de forma recorrente, enquanto mantém a tradição e a discute.

PALAVRAS-CHAVE: cânone, vestibular, tradição literāria, exclusão, descentramento.

\footnotetext{
Talvez seja correto afirmar que a memória histórica no Brasil é uma planta muito sensivel às mudanças no panorama socioeconômico e politico internacional.
}

Silviano Santiago

0 apagamento de um passado, marcado pela eliminação de diferenças e imposição de padrões alheios à afirmação das várias culturas de que se constitui a nação, pode ter contribuído para que a memória nacional pareça falha e, ao invés do ajuste de contas que deveria ocorrer com relação aos vários momentos de repressão por que passamos, a começar pelo processo de colonização portuguesa, passando pela ditadura militar, tenhamos engolido os muitos engodos com que nos fantasiaram as vărias promessas de igualdade, através da democratização. No entanto, é preciso repensar a constituição do panorama de nossa formação enquanto nação cuja memória não é uníssona, mas agonística, feita de ressignificações do passado, as quais são elaboradas por classes sociais, segmentos da nação, setores culturalmente minoritários ou hegemônicos, todos eles na maioria das vezes divergentes entre si.

* Mestre em Letras: Estudos Literários (Área de concentração: Teoria da Literatura), 2001. 


\section{EM TESE}

Belo Horizonte, v. 6, p. I-253, ago. 2003

Se a idéia de nação se reveste de um caráter consensual, paradoxalmente a nação brasileira tem sua identidade baseada no dissenso, e, só assim, ela pode ser representativa das diversidades que a compõem no seu todo. No lugar da univocidade com que acreditamos caracterizar-se a idéia de nação, faz-se necessário imaginar que, para nós, a polifonia seria a melhor representação de nossa cultura itinerante, metamórfica, que, interpretada como "uma planta menos resistente e mais sensível" (Santiago, 1998: 22), possui a capacidade da transmutação, que the dá o poder de vigorar, à margem de todas as condições desfavoráveis as quais the são peculiares, graças ao seu caráter diversificado e multicultural.

Do mesmo modo que nossa afirmação cultural comporta-se de forma agonística, em que várias culturas lutam por seus espaços, assim também deveria afirmar-se nosso cânone literário. No entanto, o conceito de obra canônica tem sido formado pelo setor letrado dessa sociedade que tem acesso ao cânone e luta por sua preservação. Tal setor, considerado elite cultural pelo fato de deter uma cultura hegemônica e não representativa do pensamento e da prática de todos os segmentos sociais, coloca, enquanto exemplo e modelo, a cultura ocidental como válida para todos os setores da nação ou sociedade.

Devido a tal fator, há espaços de canonização da literatura que recebem autorização da cultura hegemônica para agendarem a preservação dessa mesma cultura e, portanto, são mantidos e reconhecidos pelos segmentos considerados cultos da sociedade - a universidade é um desses espaços e o vestibular funciona como um instrumento da universidade na sociedade para perpetuar certa tradição cultural, inclusive uma determinada tradição literária, através da escolha de obras canônicas ou de fácil inserção no cânone, na determinação de padrões de recepção dessas obras, através da linguagem já consagrada de que elas se constituem e na forma de avaliação de sua leitura através das provas de seleção do vestibular. Contudo, no caso do vestibular da UFMG, muitas vezes, o cânone é ressemantizado, quando obras consagradas têm como parceiros textos não-canônicos ou cujo processo de consagração é ainda incipiente.

Pelo fato de a canonização não ser um processo harmonioso, mas agonístico, num país multicultural como o Brasil, há diferentes tradições que, pelo mesmo processo de organização do cânone institucionalizado, também tentam manter-se 
vivas. Entre elas, podemos situar o folclore, as lendas indígenas, os mitos africanos, a literatura feminina, por exemplo, que, por não se inserirem no padrão baseado na civilização greco-latina/judaico-cristã, são deixadas à margem do processo de canonização. Tais tradições afloram nos espaços da desconstrução dos paradigmas ocidentais, e há obras literárias que as expressaram no passado e as expressam na contemporaneidade, contrariando as expectativas dos centros hegemônicos de eleição do cânone.

Por isso, as discussões contemporâneas sobre literatura têm levantado questões sobre a concepção do objeto literário e o espaço ocupado por ele na cultura. As querelas parecem demonstrar a preocupação latente com os destinos dessa arte. E ter a intenção de resguardar um objeto significa desejar que ele se mantenha para que possa ser reutilizado. Essa reutilização processa-se através da memória como mecanismo de resgate. Feita pelo que é passado, a memória se processa no presente para se tornar passado novamente. Piglia define a tradição "como el residuo de un pasado cristalizado que se filtra en el presente" (Piglia, 1990: 61). Logo, a memória é a grande causadora da apropriação daquilo que é do outro, que é bem coletivo. Os muitos textos que os escritores leram, antes de serem escritores e quando já o eram, influenciaram suas produções, de forma perceptível ou não e, por isso, de acordo com Piglia, a tradição tem a estrutura de um sonho e passa pelo registro da memória.

Se a tradição tem essa estrutura onírica e a memória é que constrói essa tradição, instaurando um grande museu coletivo e virtual, a indicação de 128 obras literárias, nos trinta anos de vestibular unificado da UFMG, leva a entender que quando essa instituição indica a obra, ela abre espaço para a sua recomendação, por isso influencia na sua consagração e manutenção, porque até nos momentos de proposta de ruptura, é a tradição que está sendo relida no presente.

Há uma certa tradição privilegiada pois, de 1970 a 2000, a leitura da obra de Machado de Assis foi recomendada dezoito vezes, a de José de Alencar, dez vezes, seguida pela produção de Graciliano Ramos, indicada oito vezes. Juntos, os três autores mais sugeridos pela UFMG perfazem um total de 35 das 175 indicações da lista. Nessa repetição, transparece o interesse de cultuar determinados autores e certas obras, para que se mantenham sendo discutidos e conhecidos por gerações diversas. 


\section{EM TESE}

Belo Horizonte, v. 6, p. I-253, ago. 2003

Se a tradição é o passado que se filtra no presente, as releituras contemporâneas das obras tendem a alterar as leituras do passado, porque são realizadas em outras épocas, por outros indivíduos, que tiveram uma formação cultural diferente da época em que tais obras foram escritas e que, portanto, possuem outra memória. É evidente que a constante repetição de obras insere o leitor no universo da cultura geral e daquilo que representa a literatura enquanto arte. Dessa forma, a literatura passa também a ser entendida enquanto espaço de interação entre autor, leitor, obras do passado e do presente. Também, a releitura do passado, através dos recursos contemporâneos, mantém a tradição, ora através da sua continuidade, ora através da ruptura com essa tradição, o que se processa na produção de textos novos e na comparação desses textos com os do passado. É na tradição que buscamos os rastros do que somos e, se a quiséssemos negar, teríamos que tomar outra tradição. Romper e retomar é um dilema de todas as culturas, que, de certa forma, vivem uma tradição de ruptura.

Observando as obras mais indicadas, percebemos que elas são obras antológicas nos livros de Ensino Médio. Há autores sistematicamente indicados e repetidos com apenas uma obra, como é o caso de Cecília Meireles (Romanceiro da Inconfidência, quatro vezes), Monteiro Lobato (Urupês, três vezes) e Manuel Antônio de Almeida (Memórias de um sargento de milícias, três vezes). Enquanto essas estão sendo repetidas, outras do mesmo autor ou de outros autores deixam de ser indicadas e tal fato limita a inserção de obras novas, no contexto do concurso, criando um espaço de manutenção do cânone, através de sua constante retomada.

Raquel de Queiróz, Henriqueta Lisboa, Paulo Mendes Campos, Stanislaw Ponte Preta, Euclides da Cunha e outros autores canônicos não figuram na lista. No entanto, encontramos autores, que não são citados nos livros didáticos mais conhecidos do Ensino Médio e aparecem uma vez, para depois, sumirem da lista. Há nomes que aparecem na lista, como Márcio Sousa, Helena Morley, Campos de Carvalho, Cora Coralina, Luís Roncari, Carlos Herculano Lopes, Ana Cristina César, Joaquim Cardoso e Núbia N. Marques, pouco incidentes nos livros didáticos ou nem mesmo presentes neles; outros, considerados tão ou mais importantes para a compreensão e permanência da cultura brasileira, são deixados de fora. 
0 vestibular configura uma porta estreita para as obras não canônicas, mesmo para aquelas que apresentam indícios de inserção canônica, já que privilegia a tradição e utiliza a recorrência como um dos critérios de escolha: 22 escritores, com 63 obras, ocupam 105 das 175 indicações. Da lista dos escritores que aparecem uma só vez, constam nomes como Ariano Suassuna, Oswald de Andrade, Cláudio Manuel da Costa, Gregório de Matos, Tomás A. Gonzaga e Jorge Amado, entre outros. Ao repetir, insistentemente, alguns escritores, como já comentamos, a UFMG acaba por limitar a inserção de obras novas e também de outras já canonizadas. No entanto, já observamos que abre espaço para outros autores em níveis diferentes de canonização.

Por meio da lista dos eleitos da UFMG para o vestibular, percebemos que houve limitação de condições para que as minorias pudessem instruir-se e produzir literatura, dentro dos parâmetros hegemônicos porque sabemos que é possível perceber a cultura de um povo rastreando-se a sua produção literária e o que este povo lê. Se nos basearmos nessa lista canônica de 128 livros, em que é mais evidente a presença dos parâmetros da cultura branca, temos argumentos para acusar o cânone de excludente, elitista, racista, falocêntrico, logocêntrico, patriarcalista, etnocêntrico, capitalista, colonialista, imperialista e tantos outros adjetivos que possam ser gerados a partir da visão dos que defendem o espaço das minorias, caso se levasse em consideração as obras não presentes nessa listagem. Ao longo dos trinta anos de vestibular unificado, a UFMG repetiu insistentemente alguns autores e obras, indicou mais escritores do que escritoras, privilegiou as narrativas em detrimento da poesia, preferiu os escritores consagrados em relação aos que ainda não obtiveram reconhecimento. No entanto, sabemos que a solução não é rejeitar o cânone e evitar incluí-10 nas indicações de leituras obrigatórias para seleção de vestibular.

0 problema não está só no objeto canônico, mas na dificuldade que as instituições culturais, como as escolas de Ensino Fundamental e Médio, enfrentam para habilitar o jovem a manusear sua própria cultura, resgatá-la nos textos escritos e reprocessá-la de forma a torná-la sua, principalmente se considerarmos que cânone significa um perene e exemplar conjunto de obras - os clássicos, as obras-primas dos grandes mestres -, um "bem da humanidade" a ser preservado para as futuras gerações, cujo valor pode ser constantemente observado através de diversas possibilidades de leitura, em tempos diversos, por leitores também diversificados. 


\section{EM TESE}

Belo Horizonte, v. 6, p. I-253, ago. 2003

No entanto, temos consciência de que a própria atribuição do conceito de "bem da humanidade" para a literatura tem sido repensado, a partir do momento em que se questiona o próprio conceito de cultura. Reis afirma que "o lugar da literatura é a cultura" (Reis, 1992:86), já que não se pode conceber a manifestação escrita de um povo sem considerar os pressupostos culturais que a produziram. Bakhtin também pondera que "a ciência literária deve, acima de tudo, estreitar seu vínculo com a história da cultura. A literatura é uma parte inalienável da cultura, sendo impossível compreendê-la fora do contexto global da cultura de uma dada época." (1992: 362)

Se não é aconselhável separar a literatura do resto da cultura, para concordar com Reis e Bakhtin, torna-se cada vez mais difícil delimitar espaços e atribuir conceitos para cânone e para tradição, levando-se em consideração que, na era da globalização, as fronteiras da cultura foram dilatadas e os espaços antes delimitados perderam seus limites. 0 homem, ao longo de sua trajetória, rompeu com as tradições e as retomou tanto a ponto de cada ruptura ser uma busca de outra tradição, de acordo com Umberto Eco.

Observando a prática da UFMG, concluímos que não se trata de excluir obras do cânone, mas de incluir obras novas, descentralizando, dessa forma, os parâmetros de canonização na literatura, ou criando outros. Trata-se de diversificar e não de recusar experiências das margens, elegendo uma única tradição hegemônica como se ela fosse a única representante de uma nação ou de uma humanidade coesas. Essa coesão é falsa, a nação tem fronteiras culturais internas, tem grupos determinados que também têm direito de serem ouvidos e terem sua cultura valorizada.

Verificando-se a prática da UFMG, a recusa da abertura do cânone, pelo receio de sua destruição, a nosso ver, não procede, porque a leitura e o estudo de novas obras viria a enriquecê-10 e torná-10 mais representativo do ponto de vista cultural.

Sabemos que acusação que se faz de que a literatura é elitista, porque privilegia as culturas hegemônicas, reforça a reação contra o cânone e se mantém também pelo fato de que a literatura conserva seu relacionamento com toda a cultura de uma forma diferenciada e muito estreita. Não é por menos que se discutem os lugares da literatura, sugerindo-se, entre os muitos, a cultura, o não-lugar, o 
entre-lugar, não se chegando a um ponto fixo, mas a interações. E a variedade cultural não pode mais ser negada na contemporaneidade.

0 concurso vestibular da UFMG instiga a atividade da crítica literária especializada a estabelecer considerações sobre as obras indicadas, de forma a constituir-se como elemento inegável na manutenção da leitura literária e na formação do leitor na contemporaneidade, contrariando as perspectivas pessimistas daqueles que acreditam na destruição da literatura pelas interferências dos processos midiáticos da comunicação. Freqüentemente, deparamo-nos com uma pergunta sobre 0 destino do cânone, neste milênio que mal se inicia. Os prognósticos a respeito da leitura do texto literário não são animadores. Ainda mais se associarmos a trajetória da literatura ao destino do livro como o concebemos na modernidade.

Embora alguns autores se posicionem de forma pessimista com relação à prática da leitura de literatura na contemporaneidade e a identidade do jovem com ela, sabemos que o jovem hoje lê mais e mais diversificado do que no passado e o cânone deve ser questionado, reinventado, recusado ou aplaudido, e a prova de resistência aos questionamentos é um argumento para que se instaure um cânone.

"Tudo quanto pertence somente ao presente morre junto com ele" (Bakhtin, 1992: 364). Porém, se o homem tenta compreender a obra do passado com critérios apenas do passado, pouco poderá acrescentar ao que os próprios contemporâneos da obra puderam observar.

0 autor e seus contemporâneos vêem, compreendem e julgam, acima de tudo, 0 que está mais perto de sua atualidade presente. 0 autor é um prisioneiro de sua época, de sua contemporaneidade. Os tempos que the sucedem 0 libertam dessa prisão e a ciência literária tem vocação de contribuir para essa libertação. (Bakhtin, 1992:366)

Sabemos que a obra aumenta de importância mais tarde, quando se insere na grande temporalidade, conforme Bakhtin, e, muito comumente, torna-se mais rica e mais intensa e cheia de significação do que nos tempos de sua contemporaneidade. Bakhtin ressalta que "uma obra não pode viver nos séculos futuros se não se nutriu dos séculos passados" (Bakhtin, 1992:364).

Em 1984, Italo Calvino delineou seis propostas para a obra literária alcançar sucesso e seduzir o leitor, no terceiro milênio. Ele defendeu que o texto 


\section{EM TESE}

Belo Horizonte, v. 6, p. I-253, ago. 2003

capaz de exercer sedução sobre o leitor, neste milênio, deveria atender a seis princípios: leveza, rapidez, exatidão, visibilidade, multiplicidade e consistência.

A sexta proposta de Calvino, a consistência, não foi desenvolvida, pois o autor deixou-nos antes de concluir seu trabalho. Piglia propôs-se desenvolvê-la como sendo "la distancia, el desplazamiento, el cambio de lugar. Salir del centro, dejar que el lenguaje hable también en el borde, en 1o que se oye, en lo que llega de otro" (Piglia, 1999: 3). Isso significa permitir que as vozes periféricas possam narrar a memória que as vozes autorizadas não podem retomar, devido à posição centralizada que ocupam. Significa dar voz ao outro. Por isso, Piglia propõe-se a elaborar a consistência "desde Buenos Aires, escrita desde [ese] suburbio del mundo", "desde el borde de las tradiciones centrales, mirando al sesgo" (Piglia, 1999:1), porque essa posição descentralizada permitiria uma visão específica e diferente das posições dos grandes centros hegemônicos, que têm definido a trajetória do cânone literário ocidental e, por isso, o destino das obras literárias. 0 distanciamento do centro, isto é, a valorização das obras literárias das culturas marginalizadas, daria ao cânone a possibilidade de ser mais representativo, por isso, mais consistente, como deixa sugerido Calvino em sua anotação para o desenvolvimento da sexta proposta. Bem faz a UFMG ao indicar, através de seu vestibular, as obras da tradição comparadas às novas e descentralizadas, porque assim se mantém o cânone e assim se pode avaliar o destino da literatura, que é estar sendo sempre renovada, evitando que se transforme em objeto de culto de um grupo restrito que pretende, a partir de certo cânone, imobilizar os textos, em nome da originalidade, dos critérios arbitrários de valor, da influência e do centramento, aspectos insustentáveis na contemporaneidade, em que os signos se dobram sob a interação com o leitor e com o escritor, para produzir a transitoriedade dos sentidos. 
ABSTRACT :

This text discusses the notion of canon in required reading for the UFMG entrance exam from 1970 to 2000. This exam has contributed both to the inclusion of new authors in the canon of Brazilian and Portuguese literature and to the discussion of the literary canon.

KEY WORDS: canon, tradition, exclusion, descentering.

BAKHTIN, Mikhail Mikhailovith. Estética da criação verbal. Trad. Maria Ermantina Galvão Gomes Pereira. São Paulo: Martins Fontes, 1992.

BL00M, Harold. O cânone ocidental. Trad. Marcos Santarrita. Rio de Janeiro: Objetiva, 1994.

BORGES, J. L. Pierre Menard, autor de Quixote. In: Ficções. São Paulo: Globo, 1989.

CALVIN0, Italo. Seis propostas para o próximo milênio. Trad. Ivo Barroso. São Paulo: Companhia das Letras, 1997.

OLIVEIRA, Leni Nobre de. O vestibular como espaço de canonização da Literatura brasileira. Universidade Federal de Minas Gerais, 2001. 205 p. (Dissertação, Mestrado em Teoria da Literatura).

PERRONE-MOISÉS, Leyla. Altas literaturas. São Paulo: Companhia das Letras, 1998a.

- Que fim levou a crítica literária? Folha de São Paulo, 25 ago. 1996. Mais!, p. 5-9.

- A crítica literária hoje. In: Cânones e contextos. Congresso ABRALIC, 5, 1998, Rio de Janeiro. Anais... Rio de Janeiro: Universidade Federal do Rio de Janeiro, 1998b. v. 1. p. 85-89.

PIGLIA, Ricardo. < www.clarin.com.ar/diario/especiales/ viva99>.

- Memoria y tradición. In: Congresso ABRALIC, 2, 1990, Belo Horizonte. Anais... Belo Horizonte: UFMG, ago. 1990. v. 1.

REIS, Roberto. Cânon. In: Jobim, José Luís (0rg.). Palavras da crítica. Rio de Janeiro: Imago, 1992. 